\title{
PREDICTION OF MONTHLY RAINFALL IN JORDAN VALLEY USING ARTIFICIAL NEURAL NETWORK
}

\author{
Ahmad M. Dahamsheh \\ Department of Civil Engineering, Alhussein Bin Talal University, \\ P.O.Box 71111, Maan, Jordan \\ Department of Civil Engineering, Aqaba University of Technology, \\ P.O.Box 77110, Aqaba, Jordan \\ Ghassan Suleiman* \\ Department of Civil Engineering, Aqaba University of Technology, \\ P.O.Box 77110, Aqaba, Jordan \\ *Corresponding Author
}

\begin{abstract}
Artificial Neural Network (ANN) was applied to predict the long-term monthly rainfall for selected stations in Jordan valley. Meteorological data measured by Jordan meteorological department in the period between 1975 and 2005 were used. Three neurons which receive input signals of total monthly rainfall for three stations were used in the input layer of the network. One neuron, which produces corresponding output signals of the total monthly rainfall, to one station, is utilized in the output layer of the network. Finally, the values determined by the artificial neural network model were compared with the actual data. Errors obtained in this model are well within acceptable limits.
\end{abstract}

Keywords: Artificial Neural Network, Jordan Valley, Long Term Prediction, Rainfall

Cite this Article: Ahmad M. Dahamsheh and Ghassan Suleiman, Prediction of Monthly Rainfall in Jordan Valley Using Artificial Neural Network, International Journal of Civil Engineering and Technology, 11(10), 2020, pp. 31-39.

https://iaeme.com/Home/issue/IJCIET?Volume $=11 \&$ Issue $=10$

\section{INTRODUCTION}

Jordan climate is considered as an arid weather, due to the low annual rainfall precipitation in most of the country. Shortage of water resources is one of the most important issues in Jordan. The increase in population and the need to improve the living standards throughout the coming years makes the water availability issue one of the most important problems that concern, not only Jordan but the whole world nowadays. Shortage of water resources affects many important fields such as industry, agriculture and health [3]. 
Prediction models for climate parameters such as rainfall, runoff, evaporation and temperature had been studied by many scholars to improve the ability of forecasting and warning systems at meteorological departments around the globe. Many mathematical model simulations and algorithms were employed. Daily simulation for rainfall spells and amounts was presented by [1]. A nonparametric model using nearest neighbor methods was used. The model was applied into two stages. First dry and wet spell lengths are simulated conditionally. Then rainfall amounts for each month of the wet and dry spells are simulated assuming an order one Markov dependence structure. Additional variable was considered for higher order dependence model. The length of the wet spell was used for finding the rainfall distributional characteristic. The model was applied for Jordan for monthly rainfall data [7]. A fuzzy system model was developed to rainfall-runoff for Brazil Iguaçu River basin based on meteorological rain forecasts for the operational planning of hydroelectric power plants and used to compute natural flow predictions [6]. The model estimated algorithm using rainfall observation data as input. A computational system model was suggested by [8] to predict both the rainfall amount and occurrence at the same time for Santiago de Compostela airport, Spain. The classifiers performance improved using a set of predictive meteorological variables. The system was able to obtain rainfall amount and a prediction of occurrence, on the other hand, the model system was useful to be used in airport as a weather forecast and a warning system to enhance the airport operations. Moreover, L-moments method is used by [4] and the index regional frequency analysis approach which presented the development of intensity-durationfrequency (IDF) data for the State of Qatar. Data for daily rainfall from 32 stations in Qatar state and nearby Gulf country were used. It concluded that the Pearson Type 3 distribution is the best fit for 24-h duration annual maximum rainfall data in Qatar region. Prediction equation was developed which can estimate mean annual maximum rainfall with an error of about $5.5 \%$. The IDF curves will be applicable in Qatar and will provide a statistically basis for storm water design and flood.

A symbiotic adaptive neuro-evolutionary algorithm was used by [2] to predict neural network models for the River Ouse catchment. The models are used for lead times of 6 and 24 hours and compared with regular neural network models trained using back propagation. The algorithm is also modified to use different objective functions in the optimization process: mean squared error, relative error and the Nash-Sutcliffe coefficient of efficiency. In terms of overall performance, it is found that as the lead time is longer, the neural networks perform better than the conventional ones. Also, from a hydrological the sum squared error objective function does not result in the best performing model. The long-term monthly temperature and rainfall at any target point in Turkey using Artificial Neural Networks (ANN) based on the use of the neighboring measuring stations data was predicted by [5]. Meteorological data were measured by the Turkish state meteorological service between the years 1975 and 2006 using 76 measuring stations; 59 stations as training and 17 stations as testing data. The input layers of the network were used in four neurons input signals of latitude, longitude, altitude, and month. The output layer of the network was utilized in two neurons, which produce corresponding output signals of the long-term monthly temperature and rainfall. The actual data were compared with the values determined by the artificial neural network model. Obtained results using this model were very close matching the actual data. An entangled fuzzy statistical downscaling (FSD) and soft computing (SC) approaches was used by [9]. A comparison of the FSD and the neural statistical downscaling (NSD) approaches for the summer period of 12 major urban centers of São Paulostate, Brazil. The performance of FSD or NSD systems showed a good performance compared to multilinear regression ETA model for a daily rainfall forecasting. Therefore, NSD and FSD can become an alternative for achieving a correspondence from meteorological and thermo-dynamical variables to the daily rainfall variable. 
Artificial Neural Network (ANN) method was used by [10] to determine the potential of the available discharge in the long term for the purpose of Micro Hydro Power (MHP).The modeling of rainfall-runoff in the watershed of Bolon in Simalungun district of North Sumatra Province. The software was developed with Scilab mathematical open source software based on ANN algorithm. The data are record of monthly rainfall and discharge for 12 years (2001 to 2012).

In the present work, we used ANN method for prediction of long-term monthly rainfall in Jordan Valley using neighboring data based on different geographical variables such as latitude, longitude, altitude and month.

\section{DATA AND STUDY AREA}

Jordan extends over a region of roughly $90000 \mathrm{~km}^{2}$ within the semi-arid to arid climatically region in the Middle East. It is a rustic that suffers from the water deficiency and its uneven distribution. Water shortage in the country is exacerbated by its high population growth, socio-economic development and continuous degradation in water quality. Quite $90 \%$ of the country receives an annual total precipitation less than $150 \mathrm{~mm}$ on the average of that exceptional $90 \%$ evaporates back to the atmosphere.

Jordan has four climatological regions: The Ghor (JordanValley), mountains (hilly region), the Badia (desert region) and the Aqaba gulf region. The Ghor that is considered as the world's lowest valley set within the western a part of the country. It extends from the north to the south for regarding four hundred metric linear units with a breadth variable from $10 \mathrm{~km}$ in the north to $30 \mathrm{~km}$ in the south. The elevation in the Ghor changes from $420 \mathrm{~m}$ below the mean water level m.s.l. up to $170 \mathrm{~m}$ below m.s.l. Its climate is assessed as tropical, that is very hot in summer and moderate in winter with an annual precipitation of $150-400$ $\mathrm{mm}$. To the East of the Ghor is that the mountainous region that extends from North to South with elevation reaching up to $1150 \mathrm{~m}$ above m.s.l. Its climate is very delicate in summer and cold in winter. The annual precipitation changes between three hundred and $600 \mathrm{~mm}$. To the East of the mountainous region is the Badia, a semi-desert highland that is characterized by dry hot summer and comparatively cold dry winter with a precipitation of $40-100 \mathrm{~mm}$ over a year. The metropolis region, the foremost southern part within the country, is characterized by a really hot summer and a warm winter with an annual precipitation not prodigious $50 \mathrm{~mm}$. Four meteorological stations Baqura, Wadi Al Rayyan, Deir Alla and Ghor Al Safi operated by the Jordan meteorological department were utilized in this study. The stations were chosen specified they Jordan valley climatological regions in Jordan which they even have long periods of records.

\section{ARTIFICIAL NEURAL NETWORKS}

ANN models are vital tools in hydrology, meteorology and water resources related analysis studies. ANN models utilized in this study have already been well established and documented within the literature (Haykin, 1999), therefore they are not recurrent herein, however solely briefed as follows, the Feed forward back propagation (FFBP) ANN consists of three or additional layers; input layer, hidden layers and output layer, every with a definite number of neurons. In the FFBP ANN model, number of neurons within the input and output layers is taken adequate the amount of input (independent) and output (dependent) variables respectively, whereas the number of neurons in the hidden layer is subject to a trial-and-error procedure with that the error between the discovered variable and also the model output is minimized. Using a correct perform $\mathrm{f}$, the input variables $\left(\mathrm{x}_{\mathrm{i}}, \mathrm{i}=1, \ldots, \mathrm{n}\right)$ are processed in the hidden layer as

$$
z_{j}=f\left(\sum_{i=1}^{n} x_{i} w_{i j}+b_{j}\right), j=1, \ldots, h
$$

https://iaeme.com/Home/journal/IJCIET 33


Where $\mathrm{w}_{\mathrm{ij}}$ is the weight of the connection from the $\mathrm{i}^{\text {th }}$ input neuron to the $\mathrm{j}^{\text {th }}$ hidden neuron, and $b_{j}$ is the bias for the $\mathrm{j}^{\text {th }}$ hidden neuron. In this study, one hidden layer was chosen. It is noted from Eq. (1) that $h$ neurons exist in the hidden layer. The outputs of the hidden layer $\left(\mathrm{z}_{\mathrm{j}}, \mathrm{j}=1, \ldots, \mathrm{h}\right)$ are transformed to the final output by

$$
y_{k}=f\left(\sum_{j=1}^{h} z_{j} w_{j k}+b_{k}\right), k=1, \ldots, m
$$

Where $w_{j k}$ is the weight of the connection from the $j^{\text {th }}$ hidden neuron to the kth output neuron, and $b_{k}$ is the bias for the kth output neuron. It is noted from Eq. (2) that m neurons exist in the output layer. More information on this particular neural network model can be obtained from Rumelhart et al. (1986).

\section{ARTIFICIAL NEURAL NETWORK STRUCTURE, ANALYSIS AND RESULTS:}

One of the most important steps in developing a satisfactory ANN forecasting model is the selection of appropriate nodes in each layer, mentioned above, to be determined by a trialand-error effort. The use of an ANN for forecasting time series implies that the input nodes are connected to a number of past-observed values to identify the process at future time steps. It should be emphasized that it is aimed at identifying the common input variables to fit best for the types of the ANNs. Various combinations of the stations are used to construct the appropriate input structure in the monthly rainfall forecasting model. In this study four models are constructed to produce total monthly rainfall for the stations in the same region. In order to train the model 300 months are used for training and 72 months are used to test the model

The mean absolute error (MAE given as the average of the absolute values of the errors) and determination coefficient $\left(\mathrm{R}^{2}\right)$ were used to see the convergence between the observed value and the predicted value. The performance values such as MAE and $\mathrm{R}^{2}$ for the training and testing procedure are given in Table 1.

Table 1 The performance values for training and testing procedure

\begin{tabular}{|l|c|c|c|c|}
\hline \multirow{2}{*}{} & \multicolumn{2}{|c|}{ Training } & \multicolumn{2}{c|}{ Testing } \\
\cline { 2 - 5 } & $\mathbf{R}^{\mathbf{2}}$ & MAE & $\mathbf{R}^{\mathbf{2}}$ & MAE \\
\hline Model 1 & 0.95 & 8.9 & 0.98 & 7.5 \\
\hline Model 2 & 0.97 & 5.7 & 0.97 & 5.7 \\
\hline Model 3 & 0.96 & 6.1 & 0.97 & 5.4 \\
\hline Model 4 & 0.76 & 4.1 & 0.66 & 4.6 \\
\hline
\end{tabular}

\subsection{Model 1}

The objective of this model is to produce total monthly rainfall for Baqura station. Model inputs are total monthly rainfall for the Ghor Al Safi, Deir Alla and Wadi Al Rayyan stations, whereas model output is total monthly rainfall for Baqura station. The best fit structure of the ANN is obtained when 4 neurons in the hidden layer are used. The observed and predicted total monthly rainfall in the test period is illustrated in figure 1, 2 for the Baqura station. The 6-year (72- month).

Time series of the observed and the predicted monthly total rainfall are presented (Figure 1) together with the scatter diagram of the observed and the predicted rainfall (Figure 2). In the popular ANN literature, these two graphs are commonly used for comparison. The time series simply compares the observed and the predicted monthly total rainfall. The scatter diagram shows how the observed versus the forecasted precipitation scatter around the 1:1 perfect line together with the best-fit linear line of the predicted. 


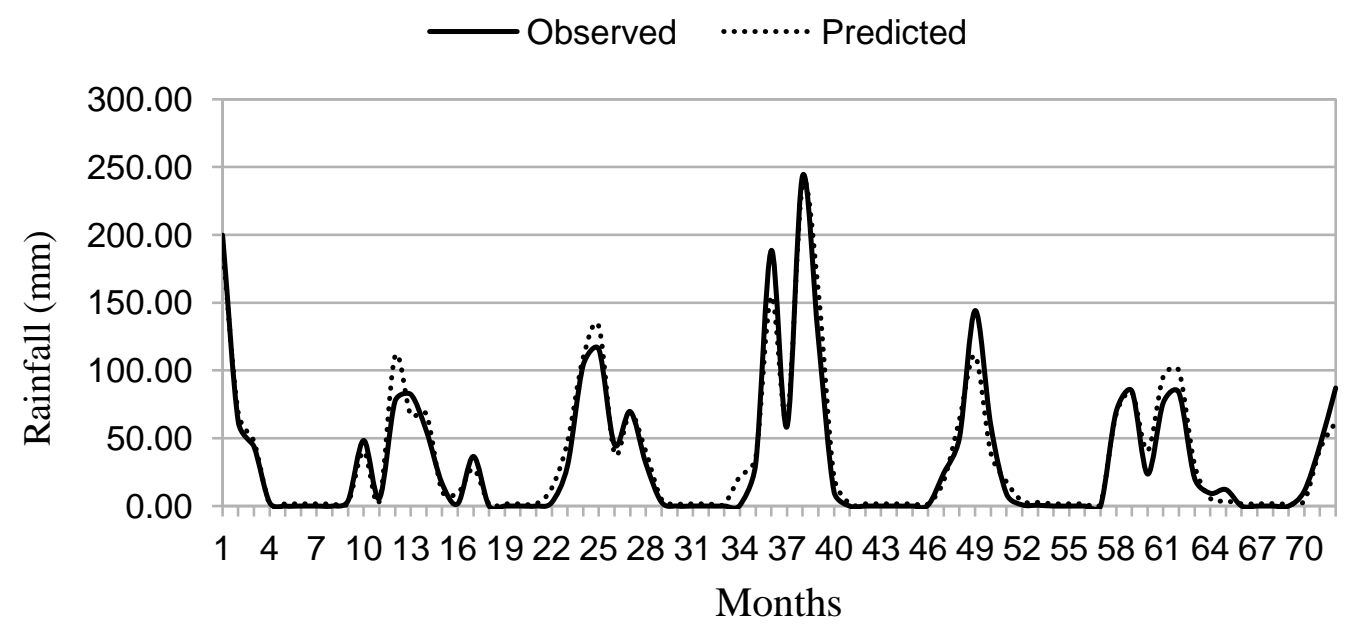

Figure 1 The predicted (dashed) and observed (solid) time series for Baqura

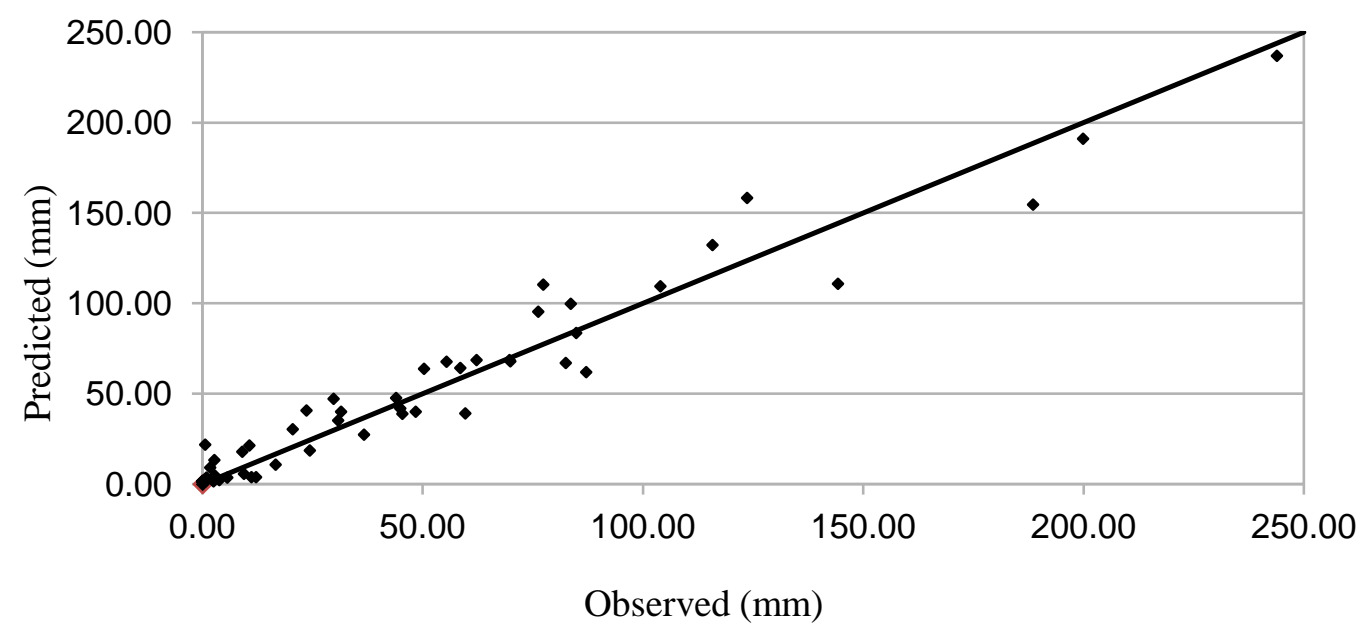

Figure 2 The scatter diagram between the predicted and observed rainfall for Baqura

\subsection{Model 2}

Total monthly rainfall of Baqura, Deir Alla and Ghor Al Safi are used as input, whereas total monthly rainfall of Wadi Al Rayyan is used as output. After trial and error procedure best fit structure of the ANN is obtained when 4 neurons in the hidden layer are used. The observed and predicted total monthly rainfall in the test period are illustrated in figure 3, 4 for the Wadi Al Rayyan station. The time series of the observed and the predicted monthly total rainfall are presented (Figure 3) together with the scatter diagram of the observed and the predicted rainfall (Figure 4). 
Prediction of Monthly Rainfall in Jordan Valley Using Artificial Neural Network

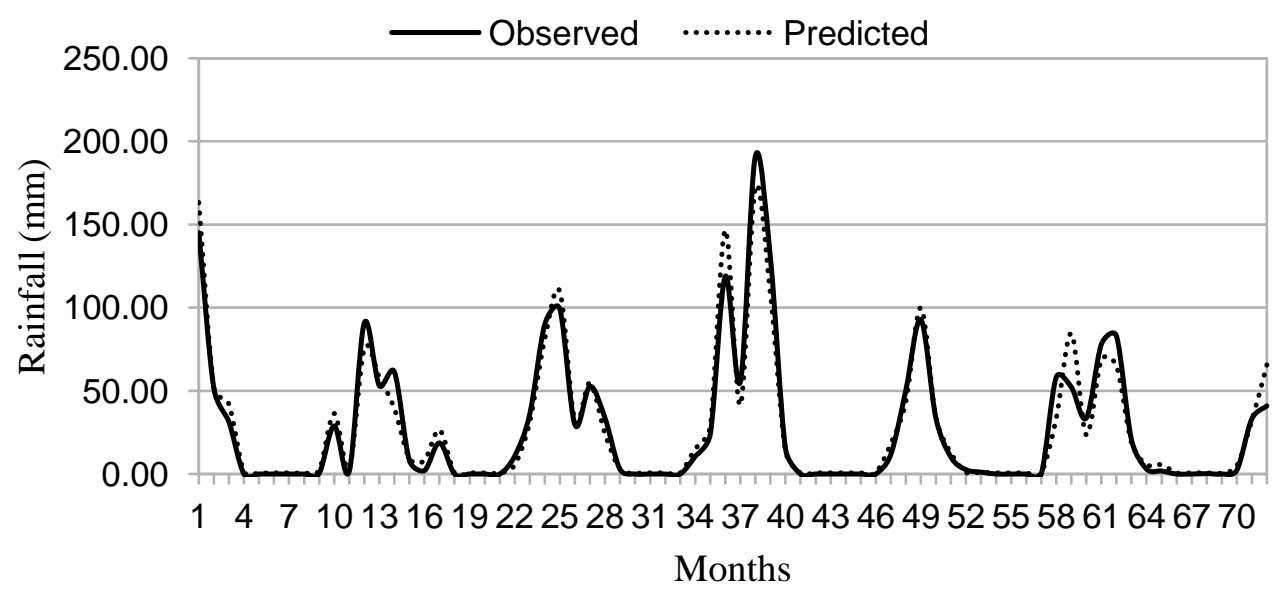

Figure 3 The predicted (dashed) and observed (solid) time series for Wadi Al Rayyan

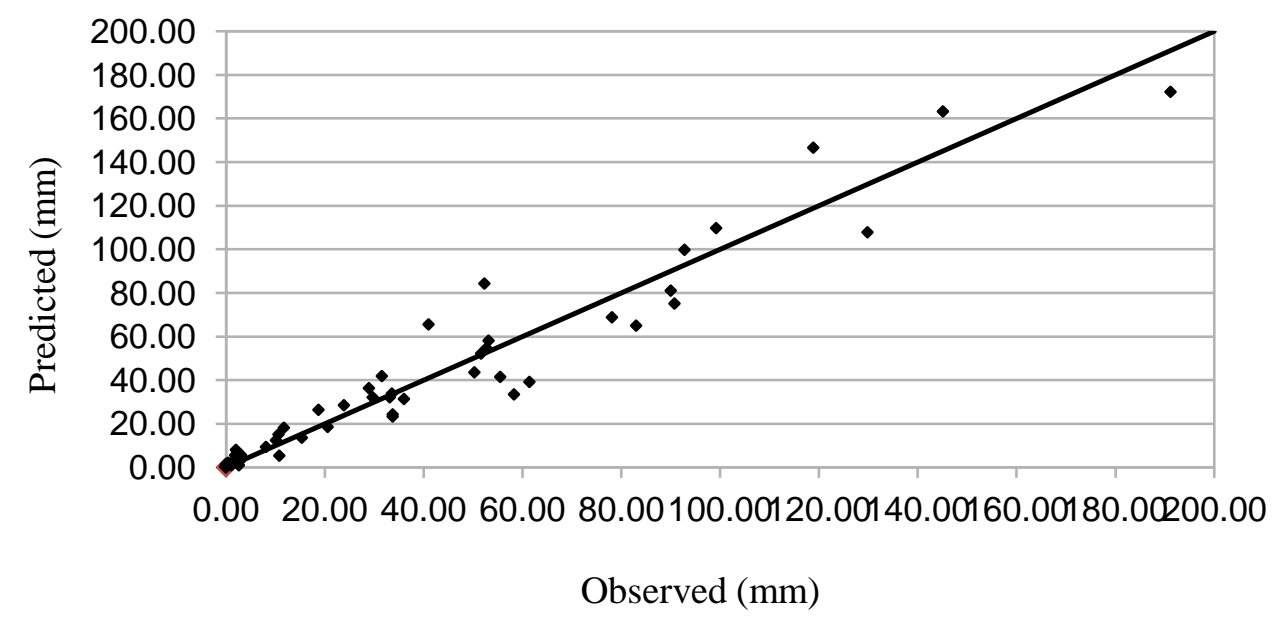

Figure 4 The scatter diagram between the predicted and observed rainfall for Wadi Al Rayyan

\subsection{Model 3}

Total monthly rainfall of Baqura, Wadi Al Rayyan and Ghor Al Safi are used as input, whereas total monthly rainfall for Deir Alla is used as output. After trial and error procedure best fit structure of the ANN is obtained when 7 neurons in the hidden layer are used. The observed and predicted total monthly rainfall in the test period are illustrated in figure 5, 6 for the Deir Alla station. The time series of the observed and the predicted monthly total rainfall are presented (Figure 5) together with the scatter diagram of the observed and the predicted rainfall (Figure 5). 


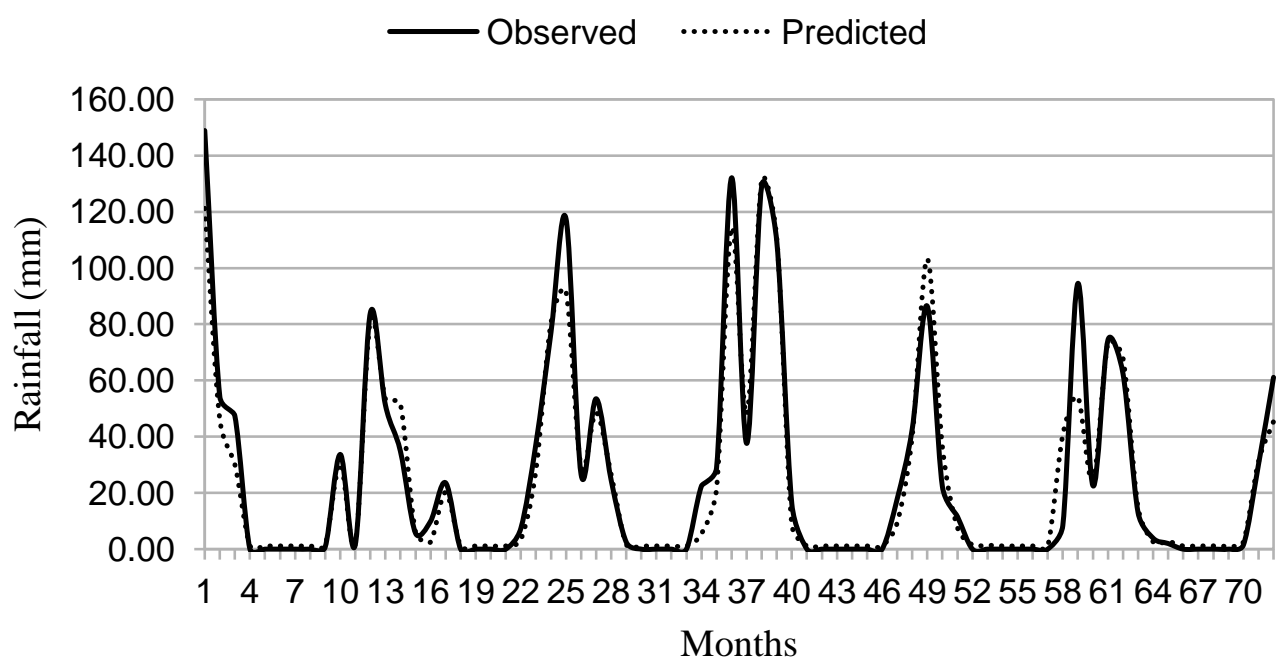

Figure 5 The predicted (dashed) and observed (solid) time series for Deir Alla

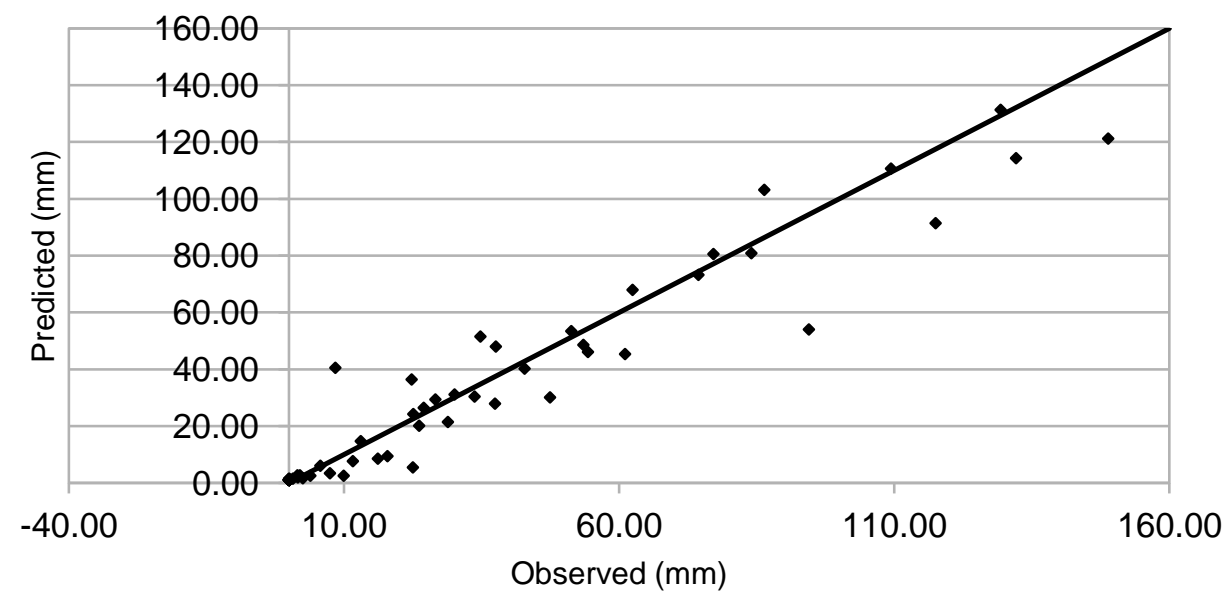

Figure 6 The scatter diagram between the predicted and observed rainfall for Deir Alla

\subsection{Model 4}

Total monthly rainfall of Baqura, Wadi Al Rayyan and Deir Alla are used as input, whereas total monthly rainfall for Ghor Al Safi is used as output. After trial and error procedure best fit structure of the ANN is obtained when 9 neurons in the hidden layer are used. The observed and predicted total monthly rainfall in the test period are illustrated in figure 7, 8 for the Ghor Al Safi station. The time series of the observed and the predicted monthly total rainfall are presented (Figure 7) together with the scatter diagram of the observed and the predicted rainfall (Figure 8). 


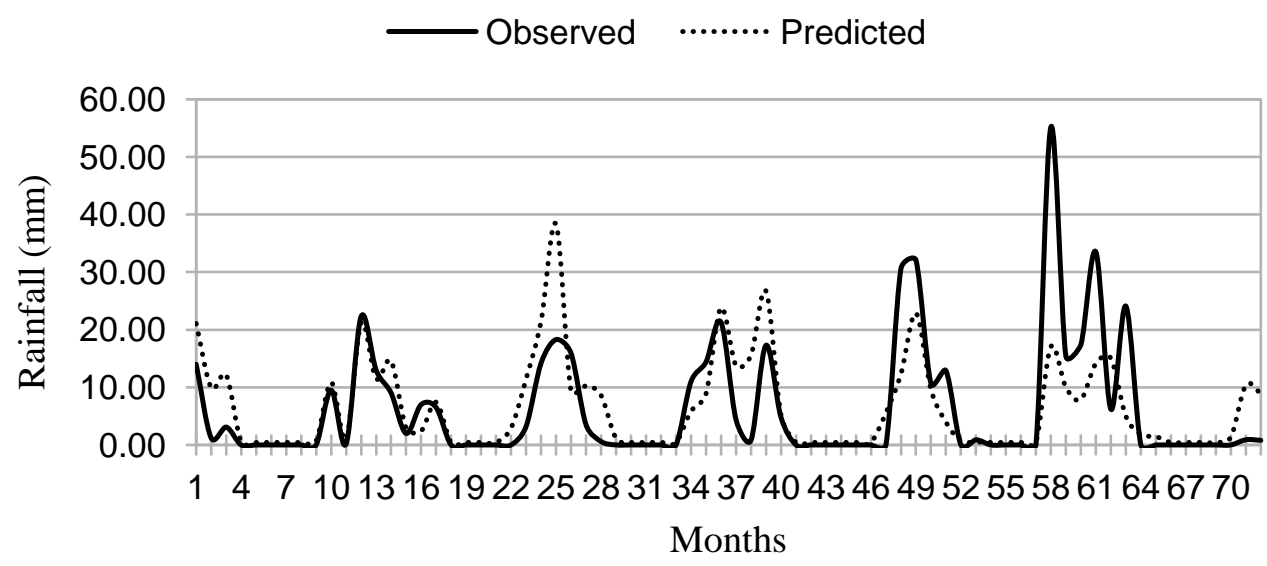

Figure 7 The predicted (dashed) and observed (solid) time series for Ghor Al Safi

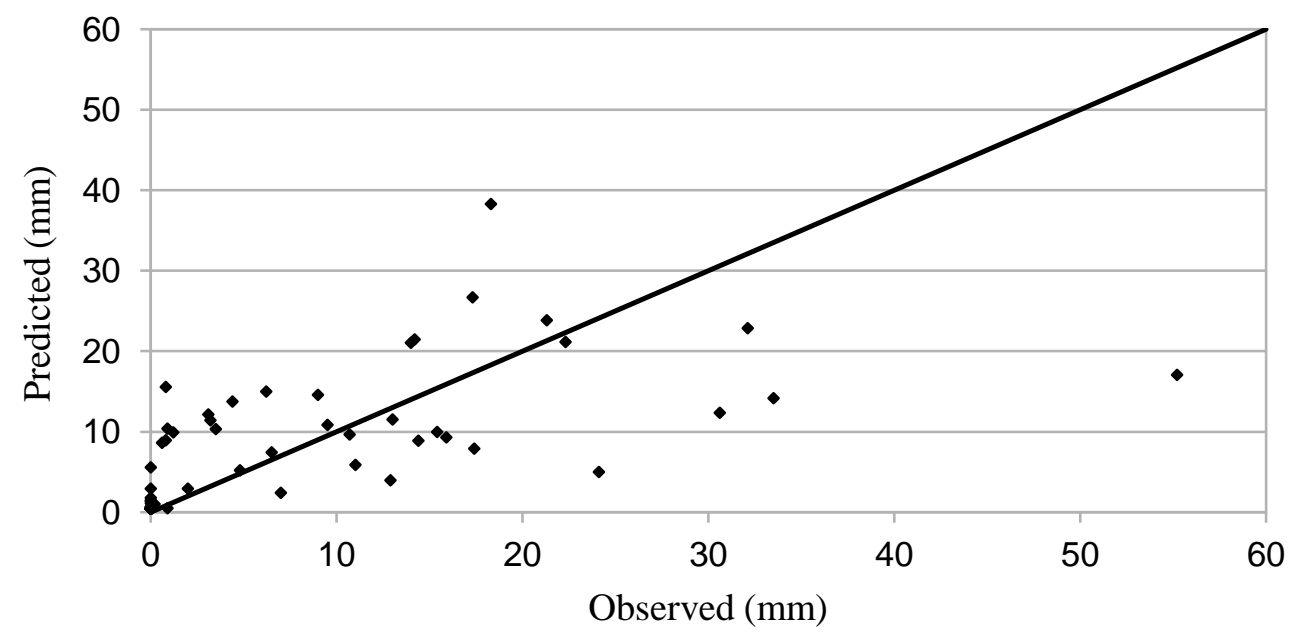

Figure 8 The scatter diagram between the predicted and observed rainfall for Ghor Al Safi

The accuracy of the models was compared with respect to determination coefficient $\left(\mathrm{R}^{2}\right)$ and mean absolute error (MAE) are provided in table 1 for the Baqura, Wadi Al Rayyan, Deir Alla and Ghor Al Safi stations. In the result of the training procedure, it can be seen in table 1 that the MAE values ranged from 4.1 to 8.9 differ from the actual value for the long term monthly rainfall, while the MAE values of the testing procedure ranged from 4.6 to 7.5 differ from the actual value for the long term monthly rainfall.

The determination coefficients $\left(\mathrm{R}^{2}\right)$ between the observed and predicted value for the long term monthly rainfall were found to be 0.97 and 0.76 in the result of training procedure. While the $\mathrm{R}^{2}$ values of the testing procedure between the observed and predicted value for the long term monthly rainfall were found to be 0.98 and 0.66 . Another significant point in this study, as seen in Table 1 the performance values of the testing procedure are in general better than the performance values of the training procedure. The scatter diagram (figures 2, 4, 6,8) shows how the observed versus the predicted precipitation scatter around the 1:1 perfect line together with the best-fit linear line of the forecast. The time series of the network predictions against the observed values were drawn for all target stations in order to indicate the performance of the ANN method. It can be seen from the (figures $1,3,5,7$ ) that the results of prediction have fairly close agreement with the corresponding measurements for all stations. 


\section{CONCLUSION}

An ANN it simply establishes a relation between the input and output data. Moreover, the model is less sensitive to error in the input data and processes data in parallel. In this study, the black box ANN approach was used to predict monthly rainfall time series for the Jordan valley rain gauges. In this article, ANNs were applied to predict the annual total monthly rainfall at any target point of Jordan valley. Neighboring stations meteorological data (annual total monthly rainfalls) were used as an input file for this model. It can be complete that the ANN methodology looks a robust tool in predicting the monthly rainfall of any specific point with no measuring depending on its neighboring stations variables. The methodology presented herein not only is applicable in other regions with different climatic regimes, but also it could be utilized in other hydrological processes such as sediment, runoff etc.

\section{REFERENCES}

[1] Sharma Ashish, Lall Upmanu, (1999),"A nonparametric approach for daily rainfall simulation", Mathematics and Computers in Simulation, Volume 48, Issues 4-6, Pages 361371.

[2] Dawson Christian W., See Linda M., Abrahart Robert J., Heppenstall Alison J.,(2006)," Symbiotic adaptive neuro-evolution applied to rainfall-runoff modelling in northern England", Neural Networks, Volume 19, Issue 2, Pages 236-247.

[3] Aksoy, H., \& Dahamsheh, A. (2018). Markov chain-incorporated and synthetic data-supported conditional artificial neural network models for forecasting monthly precipitation in arid regions. Journal of hydrology, 562, 758-779.

[4] Al Mamoon Abdullah, Joergensen Niels E., Rahman Ataur, Qasem Hassan, (2014)," Derivation of new design rainfall in Qatar using L-moment based index frequency approach", International Journal of Sustainable Built Environment, Volume 3, Issue 1, June 2014, Pages 111-118.

[5] Bilgili M.,Sahin B,(2010)," Prediction of Long-term Monthly Temperature and Rainfall in Turkey", Energy Sources, Part A, Volume 32, Pages 60-71. DOI: 10.1080/15567030802467522.

[6] Evsukoff G. Alexandre, CataldiMarcio, Lima Beatriz S.L.P. de, (2012)“A multi-model approach for long-term runoff modeling using rainfall forecasts”, Expert Systems with Applications, Volume 39, Issue 5, Pages 4938-4946.

[7] Dahamsheh, A., \& Aksoy, H. (2014). Markov chain-incorporated artificial neural network models for forecasting monthly precipitation in arid regions. Arabian Journal for Science and Engineering, 39(4), 2513-2524.

[8] Sánchez-Monedero J., Salcedo-Sanz S., Gutiérrez P.A.,Casanova-Mateo C.,Hervás-Martínez C., (2014), "Simultaneous modelling of rainfall occurrence and amount using a hierarchical nominal-ordinal support vector classifier', Engineering Applications of Artificial Intelligence, Volume 34, Pages 199-207.

[9] Valverde M.C., Araujo Ernesto, Velho H. Campos,(2014)" Neural network and fuzzy logic statistical downscaling of atmospheric circulation-type specific weather pattern for rainfall forecasting", Applied Soft Computing, Volume 22, Pages 681-694.

[10] Setiono, Hadiani Rintis,(2015)," Analysis of Rainfall-runoff Neuron Input Model with Artificial Neural Network for Simulation for Availability of Discharge at Bah Bolon Watershed", Procedia Engineering, Volume 125, Pages 150-157. 